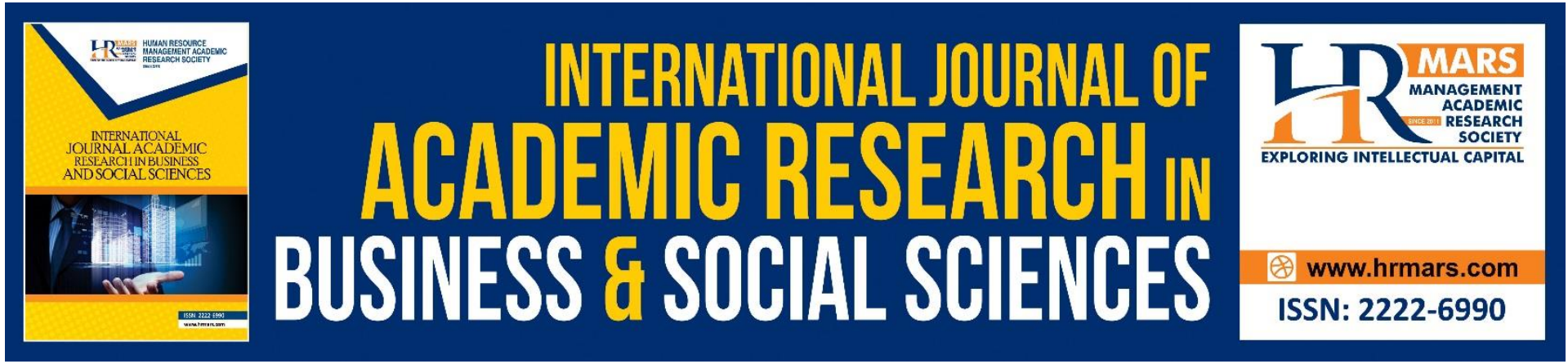

\title{
The Relationship Between Medication Adherence and Health-Related Quality of Life among Type 2 Diabetes Mellitus (T2DM) Patients
}

Norfaezah Zakaria, Nor Firdous Mohamed, Nur Amani Ahmad Tajuddin, Nor Ashikin Md Sari

To Link this Article: http://dx.doi.org/10.6007/IJARBSS/v11-i7/10525

DOI:10.6007/IJARBSS/v11-i7/10525

Received: 18 May 2021, Revised: 20 June 2021, Accepted: 04 June 2021

Published Online: 28 July 2021

In-Text Citation: (Zakaria et al., 2021)

To Cite this Article: Zakaria, N., Mohamed, N. F., Tajuddin, N. A. A., \& Sari, N. A. M. (2021). The Relationship Between Medication Adherence and Health-Related Quality of Life among Type 2 Diabetes Mellitus (T2DM) Patients. International Journal of Academic Research in Business and Social Sciences, 11(7), 670680.

Copyright: @ 2021 The Author(s)

Published by Human Resource Management Academic Research Society (www.hrmars.com)

This article is published under the Creative Commons Attribution (CC BY 4.0) license. Anyone may reproduce, distribute, translate and create derivative works of this article (for both commercial and non-commercial purposes), subject to full attribution to the original publication and authors. The full terms of this license may be seen

at: http://creativecommons.org/licences/by/4.0/legalcode

Vol. 11, No. 7, 2021, Pg. 670 - 680

http://hrmars.com/index.php/pages/detail/IJARBSS

JOURNAL HOMEPAGE

Full Terms \& Conditions of access and use can be found at http://hrmars.com/index.php/pages/detail/publication-ethics 


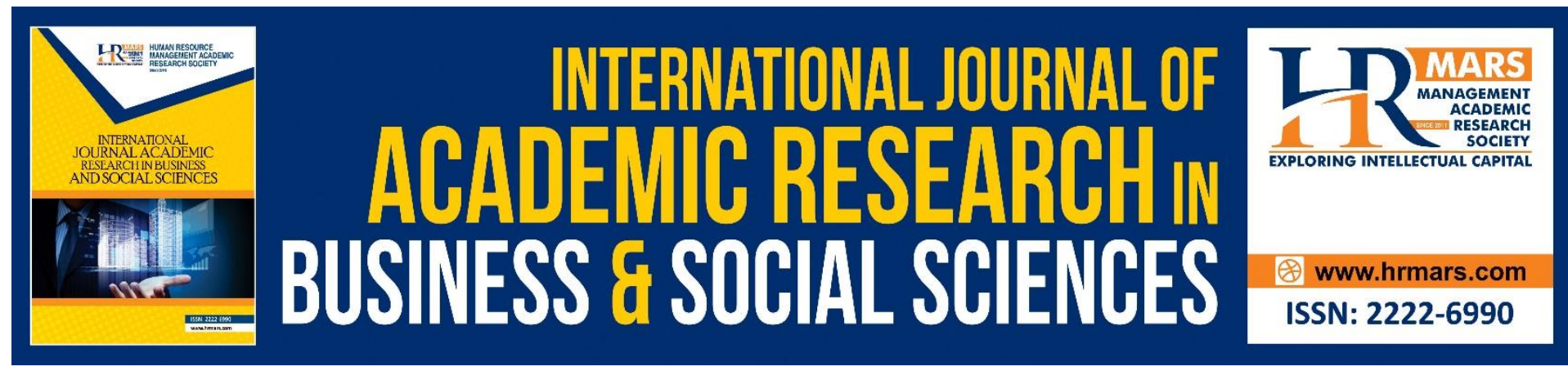

\title{
The Relationship Between Medication Adherence and Health-Related Quality of Life among Type 2 Diabetes Mellitus (T2DM) Patients
}

\author{
Norfaezah Zakaria ${ }^{1}$, Nor Firdous Mohamed ${ }^{1}$, Nur Amani Ahmad \\ Tajuddin², Nor Ashikin Md Sari² \\ ${ }^{1}$ Faculty of Human Development, Sultan Idris Education University, Malaysia, ${ }^{2}$ Department \\ of Primary Care, University Malaya Medical Center, Malaysia
}

\begin{abstract}
This study aimed to investigate the relationship between medication adherence and healthrelated quality of life among Type 2 Diabetes Mellitus (T2DM) patients. A correlational survey design was used in this study. The study was conducted through assisted questionnaire administration via face to face with 188 T2DM patients. The questionnaire used was the Medication Compliance Questionnaire (MCQ) and Diabetes Quality of Life revised version (DQoL-R). Descriptive analysis, Crosstabs analysis and Chi-Square test was used to run the data of this study. Result shows the average age of the participants were 64.60 years old and a significant relationship was found between medication adherences with the domain Worry in diabetes quality of life. In conclusion, this study may provide a significant finding on quality of life factors which also need to be appropriately intervene in order to improve medication adherence among type 2 diabetes patients in Malaysian health care.
\end{abstract}

Keywords: Medication Adherence, Health-Related Quality of Life, Medication Compliance Questionnaire, Diabetes Quality of Life Revised Version, Type 2 Diabetes Patients

\section{Introduction}

Type 2 diabetes mellitus (T2DM) is a complex and well-known chronic disease that was caused by failure of pancreas producing poor amount of insulin or the body cells could not use the intake of insulin effectively from the pancreas (Hurtado \& Vella, 2018). It also can be found in other metabolic conditions such as hypertension and obesity, whereby usually coexist in individuals with T2DM.

In Malaysia, based on data recorded in the National Mortality and Morbidity Surveys (NHMS) by the Ministry of Health $(\mathrm{MOH})$ shows the number of diabetes patients increased past few years, it was reported that in 2006 there was $11.6 \%$ (Institution of Public Health, 2006), 15.2\% in 2011 (Institute of Public Health, 2011) and recently 17.5\% in 2015 (National Health and Morbidity Survey, 2015). Globally, it was estimated that people to get diabetes would increase to 693 million by 2045 (Cho, Shaw, Karuranga, Huang, da Rocha Fernandes, Ohlrogge \& Malanda, 2018). Thus, these percentages indicated a large impact on the increasing number of T2DM patients in a growing population country such as Malaysia. 
Based on a study by Sefah, Okotah, Afriyie and Amponash (2020), the management of diabetes mellitus (DM) include pharmacotherapy. Some of the pharmaco-therapeutic approach included was the use of oral medication (anti-diabetic drugs), exogenous, insulin and lipid lowering drugs. A major challenge to the management of diabetes was the nonadherence towards the therapy. On average, $50 \%$ of the new medication users would fail to adhere to at least $80 \%$ of their prescribed drugs during the first year of therapy (Sapkota, Brien, Greenfield \& Aslani, 2015). In Malaysia, it was reported that $47 \%$ to $53 \%$ of diabetes patients were non-adherent towards their medication (Khoo, Lee, Sararaks, Samad, Liew, Cheong \& Ismail, 2012; Chew, Lai \& Ng, 2020).

In addition, without a proper medical intervention or therapy, diabetic patients may suffer with various type of a long-term diabetic complications in their life. As a result of these long-term complications, it could give a negative impact on the health outcomes and quality of life among the diabetic patients. The requirement of tiresome diabetes self-care such as adhere with medications can lead to psychological problem like depression and it will affect the patient's adherence towards their diabetic treatment (Bujang, Ismail, Hatta, Othman, Baharum, \& Lazim, 2017).

Thus, it is worth for the researcher to investigate whether the T2DM patients in University Malaya Medical Center (UMMC) were involved with these problems and if there is evidence of involvement, does the quality of life is related with the medication adherence behavior in T2DM patients. Overall, this study has taking into consideration on the patient's adherence towards medication and health-related quality of life as an initiative to minimize the T2DM risk, reducing the burden faced by the patients and improve the health care system.

\section{Literature Review}

Medication adherence is an important key that determine the therapeutic success and the effectiveness of the treatment in patients with chronic diseases such as type 2 diabetes mellitus (Saidi, Sabran, Razali, Salleh, Soe \& Jamaludin, 2019). There are several factors which influence medication adherence among the type 2 diabetes patients such as information on medication, experience and complication with medication, support for medication behavior and routines in medication behavior (Borgsteede, Westerman, Kok, Meeuse, de Vries \& Hugtenburg, 2011; Aloudah, Scott, Aljadhey, Araujo-Soares, Alrubeaan \& Watson, 2018). These shows that the knowledge, attitudes and practices of the patients plays an important role on the treatment outcomes.

Moreover, for patients who did not adhere with their medications, they were prone to develop one or multiple types of comorbidities (Iglay, Hannachi, Joseph Howie el al., 2016; Lin, Kent, Winn, et al., 2015). As patients with T2DM was exposed to chronic hyperglycemia, it could result in micro-vascular complication such as visual impairment, diabetic foot problems, and kidney functions (Hurtado \& Vella, 2018). A study by Muhamad, Mutalip, Mustapha, et al (2019) proves the presence of comorbidities was significantly associated with diabetic complications and the commonest comorbidity were hypertension, hyperlipidemia and obesity. These shows that, T2DM patients need to be more concern on their health conditions as they were prone to get more critical illnesses.

Besides that, a study conducted by Jannoo, Wah, Lazim and Hassali (2017) reported T2DM patients with higher levels of medication adherence had lower levels of diabetesspecific distress. The study explained that medication-focused strategy among T2DM patients was important in order for the individual able to cope better with the diabetes distress. The result of the study also shows that diabetes-specific distress was negatively associated with 
health-related quality of life. With that, patients should be advised to have a high medication adherence to endure less distress and experience a better quality of life.

In addition, a research by Khayyat, Mohamed, Khayyat, Alhazmi, Korani, Allugmani \& Hadi (2019) proves that patients with long-term diagnosis of T2DM and adhere towards their medication had a significantly better quality of life compared to those who are non-adherent towards their medications. Based on the findings of the study, patients who adhere towards their medication were more likely to enjoy their life. Meanwhile, patients who were nonadherence towards the medications only leads to disease related complications. With that, the patient would tend to face an uncontrolled disease condition which also gives a major impact on the patient's quality of life.

\section{Methodology}

This study uses the quantitative correlational survey design (Apuke, 2017). The patients were required to complete the Medication Compliance Questionnaire (MCQ) and Diabetes Quality of Life revised version questionnaire (DQoL-R) through an assisted questionnaire administration method.

\section{Research Samples}

The targeted sample for this study were Type 2 Diabetes Mellitus (T2DM) outpatients in University Malaya Medical Center (UMMC) regardless of gender, race or ethnicity (Malay, Chinese, Indian or Others). Eligible participants must be 1) an adult above 20 years and older, 2) diagnosed with T2DM, 3) currently taking at least one oral diabetes medication or insulin injection daily, 4) able to understand Malay or English language as the items asked were in both languages, 5) level of glycosylated haemoglobin $(\mathrm{HbA} 1 \mathrm{c}) \geq 6.5 \%, \mathrm{BMI}>23 \mathrm{~kg} / \mathrm{cm}^{2}$ (National Diabetes Registry Report, 2011). Patients were excluded if 1) pregnant, 2) too ill to participate, 3) unable to speak or understand Malay or English 4) currently did not taking or prescribed any oral diabetes medication (Shiyanbola et al., 2018).

The sample size was calculated using G*Power 3.1.9.2 software, with an estimated effect size of $r=0.25$, a power of 0.95 and significance at 0.05 . The estimated sample size is 200. By taking into considerations $20 \%$ of data being incomplete or missing in patient medical records, the sample size was 240 (Conn \& Ruppar, 2017). A pilot study was conducted with a total of 52 patients. With that, it makes the amount of 188 patients that will be counted in the main study. The sample was taken with multiple visits to UMMC.

\section{Pilot Test}

The pilot test for this study was conducted using Medication Compliance Questionnaire (MCQ) and the revised version of Diabetes Quality of Life (DQoL) on 188 Type 2 Diabetes Mellitus (T2DM) patients. It was reported the value of Cronbach's alpha for MQC was $\alpha=0.820$. It shows that the value of the internal consistency is acceptable. In addition, for DQoL, the value of Cronbach's alpha was $\alpha=0.819$. The result also indicates an acceptable internal consistency.

\section{Instrument}

\section{Medication Compliance Questionnaire, MCQ (Ramli, Ahmad and Paraidathu, 2012)}

The questionnaire was used to measure a patient's adherence towards their medication. It is a 7-items self-report questionnaire that modified and validated using two different adherence questionnaires, the Hill-Bone Adherence to Blood Pressure Therapy Scale 
and the 8-item Morisky Medication Adherence Scale on the hypertension population in Malaysia, by using a 5-point Likert scale. A full score of 28 or a score of 27 (due to 1 point deducted from any one of the "unintentional adherence" questions, which were question 1 or question 6), were defined as adherence. A score of 26 and below was categorized as nonadherence. Cronbach's alpha was calculated to be 0.782 , reflecting the good internal consistency and reliability. Interrater agreements (between the two interviewers) indicated good consistency with the Kappa value of 0.796. Approval to use the medication adherence scale was obtained from the developer (Ramli, Ahmad, \& Paraidathathu, 2012).

\section{Diabetes Quality of Life revised version, DQoL (Bujang, Adnan, Hatta et.al, 2018)}

The questionnaire was used to measure health-related quality of life among diabetes patients based on three main domains which are satisfaction (S), impact (I) and worry (W) (DCCT Research Group, 1988). The revised version of DQoL measure was adapted in a Malaysian study and modified into a 13-items self-report questionnaire from the original version of DQoL. (Bujang, Adnan, Hatta, Bariyyah, Ismail \& Lim, 2018). It still measured the three main domains from the previous DQoL which were satisfaction (S), impact (I) and worry (W). For the domain satisfaction (S), it contained 6 item, impact (I) contains 4 items and worry (W) contains 3 items. The response for the $S$ and I items was measured on a scale of 1 to 5 and $W$ is measured on a scale 0 to 5 . A higher average score indicates a poorer quality of life (Bujang, Ismail, Hatta, Othman, Baharum, \& Lazim, 2017).

\section{Statistical Analysis}

The Statistical Package for Social Science (SPSS) version 23.0 was used to key in the data raw data obtained from the participants. However, any missing data or incomplete survey will be discarded. A descriptive analysis was used to report the socio-demographic status, Crosstabs analysis and Chi-Square test was used to analyze the relationship between medication adherence and health-related quality of life among T2DM patients.

\section{Result}

\section{Sample's Socio-demographic Profile}

In Table 1, the number of samples ( $\mathrm{n}$ ) and percentages (\%) on age, race, sex, highest level of education, marital status, location, working status, comorbidities and routes of medication were presented. The total sample used in the study was $188 \mathrm{~T} 2 \mathrm{DM}$ patients. Based on Table 1 , the average age of the participants in this study were $M=64.60$ years old. Majority of the sample were covered by the female population with $52.7 \%(n=99)$, meanwhile for the male population only covers $47.3 \%(n=89)$. Moreover, the samples consist of participants from different racial background. Most of the participants were Malay with $43.6 \%(n=82)$, followed by Indian, 39.4\% ( $n=77)$, Chinese, $16.0 \%(n=30)$ and others $1.1 \%(n=2)$.

The highest level of education among the participants were mostly covered until secondary school with $53.2 \%(n=100)$ and only $2.7 \%(n=5)$ of the patients were not getting any proper education. In addition, based on the marital status, $9.20 \%$ ( $n=173$ ) of the participants were already married and a total of $8 \%(n=15)$ were still single and not married. Furthermore, most of the participants were found living in an urban location area, $88.3 \%$ ( $n=$ 166) rather than the rural location area with $6.9 \%(n=13)$.

Moreover, the working status of the participants shows $72.3 \%(n=136)$ of them were not working and there were $27.7 \%(n=52)$ of the participants were still working. Furthermore, hypertension is the most common comorbidities reported among the $67 \%(n=126)$ of the 
participants and $55.9 \%(n=105)$ of the participants were diagnose with other type of comorbidities instead of hyperlipidemia and dyslipidemia. Lastly, 66\% ( $n=124)$ of the participants were taking only oral anti-diabetic medications and only $29.3 \%(n=55)$ of the participants were taking their oral medication together with insulin injection.

Table 1. Sample's Sociodemographic Profile $(\mathrm{N}=188)$

\begin{tabular}{llll}
\hline Variable & & $\mathrm{n}$ & Percentage, $\%$ \\
\hline Age & Male & & Mean $=64.60$ \\
Sex & Female & 89 & 47.3 \\
Race & Malay & 99 & 52.7 \\
& Chinese & 82 & 43.6 \\
& Indian & 30 & 16.0 \\
Highest level of education & Others & College/Matriculation/ & 39.4 \\
& University & 2 & 1.1 \\
& Secondary school & 61 & 32.4 \\
& Primary school & 100 & \\
Marital status & None & 22 & 53.2 \\
& Married & 5 & 11.7 \\
\multirow{5}{*}{ Location } & Single & 173 & 92.7 \\
& Not married & 10 & 5.3 \\
Working status & Urban & 5 & 2.7 \\
& Semi-urban & 166 & 88.3 \\
Comorbidities & Rural & 9 & 4.8 \\
& Working & 13 & 6.9 \\
& Not working & 52 & 27.7 \\
Routes of Medication & Hyperlipidemia & 136 & 72.3 \\
& Hypertension & 43 & 22.9 \\
& Dyslipidemia & 126 & 67.0 \\
& Others & 5 & 2.7 \\
& Oral only & 105 & 55.9 \\
& Injection only & 124 & 66.0 \\
& Oral \& injection & 9 & 4.8 \\
& & 55 & 29.3 \\
\hline
\end{tabular}

\section{The Prevalence Rate of Medication Adherence}

The prevalence rate of medication adherence was administered by using Medication Compliance Questionnaire (MCQ). The response status to the questions in MCQ are presented in Table 2, whereby a score of 27 was considered adherence. There was a total of 119 (63.3\%) number of patients who are adhere towards their medication intake and 69 $(36.7 \%)$ of the patients were categorized as non-adherent.

Table 2. Summary of the MCQ score and adherence status $(\mathrm{N}=188)$

\begin{tabular}{llll}
\hline Total score (28 points) & $\mathrm{n}$ & Percentage, $\%$ & Status \\
\hline$<26$ & 69 & 36.7 & Non-adherent \\
$>27$ & 119 & 63.3 & Adherent \\
\hline
\end{tabular}

Notes: Non-adherence is defined as a score of 26 and below, whereas adherence is defined as a patient with a score of 27 and higher. 


\section{The Prevalence of Health-Related Quality of Life}

The analysis of health-related quality of life was performed by using the Diabetes Quality of Life Revised version (DQoL). Figure 3 shows the level quality of life among the patients with T2DM based on the three domains in DQoL. It was reported that the highest percentage $68.1 \%(n=128)$ patients were have a good level quality of life on "Worry" domain, $62.2 \%(n=117)$ were having a good level quality of life and $37.8 \%(n=71)$ of the patients were having poor level quality of life in "Impact" domain and the least percentage, $59.6 \%$ (n $=112$ ) of the patients were having a good level quality of life under "Satisfaction" domain. Overall, the total DqoL shows that $56.4 \%(n=106)$ of the patients were having a good level quality of life and $43.6 \%(n=82)$ patients were having poor level quality of life.

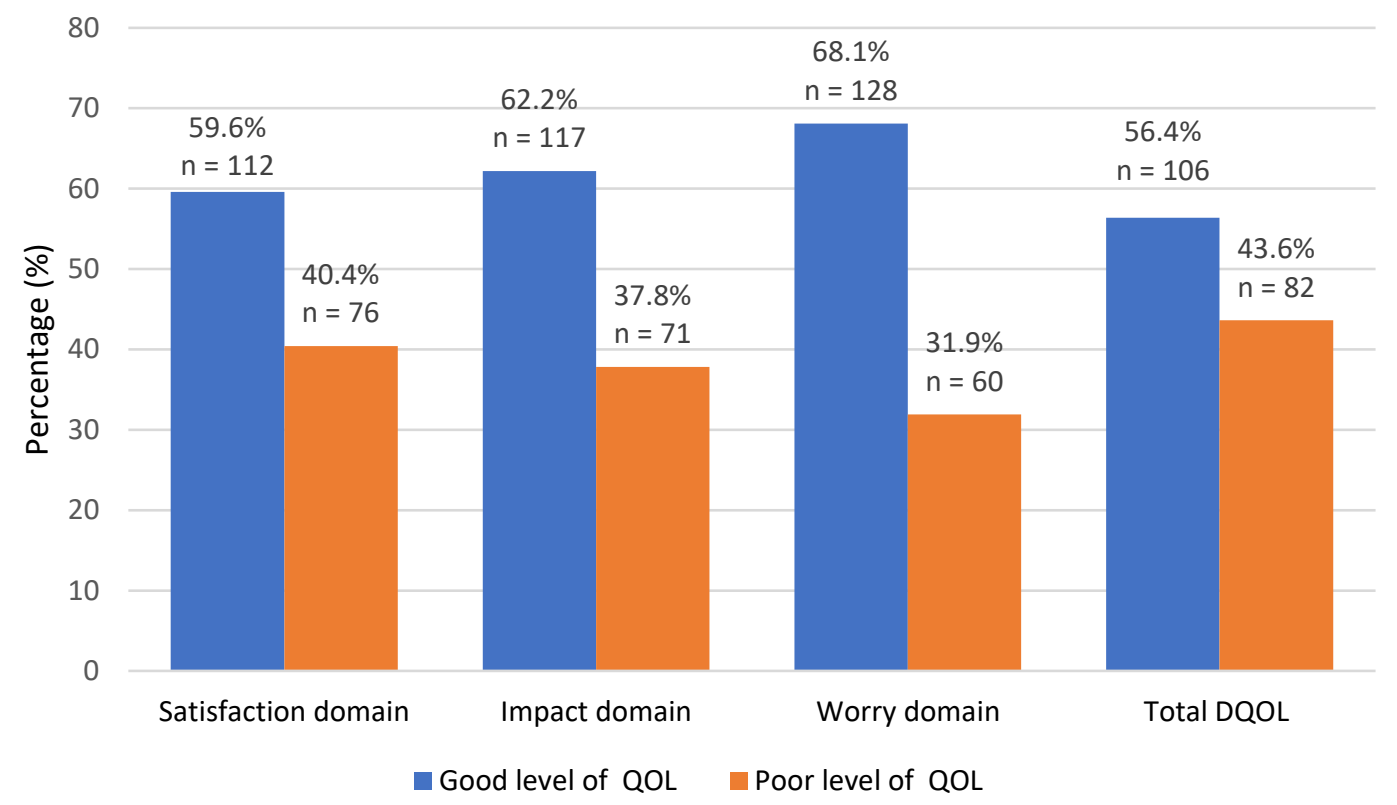

Figure 3. Prevalence of Health-Related Quality of Life $(\mathrm{N}=188)$

\section{The Percentage of Medication Adherence and Non-adherence among T2DM patients with} Level of Health-Related Quality of Life

The Table 4 shows the percentage of T2DM patients' medication adherence with the level of health-related quality of life. A total of 67.9\% T2DM patients who adhere towards their medication and have a good level of health-related quality of life. Furthermore, the table shows the percentage for T2DM patients who did not adhere towards their medication and have a poor level medication adherence is $42.7 \%$. The total percentage for T2DM patients who adhere and obtain a quality of life is $63.3 . \%$, meanwhile those who are non-adhere towards their medication and obtain a quality of life is only $36.7 \%$. 
INTERNATIONAL JOURNAL OF ACADEMIC RESEARCH IN BUSINESS AND SOCIAL SCIENCES

Vol. 11, No. 7, 2021, E-ISSN: 2222-6990 @ 2021 HRMARS

Table 4. Percentage of Medication Adherence and Level of Health-Related Quality of Life

\begin{tabular}{|c|c|c|c|c|c|}
\hline & & & \multicolumn{2}{|c|}{ DQoL } & \multirow[b]{2}{*}{ Total } \\
\hline & & & Good level & Poor level & \\
\hline \multirow{6}{*}{$\begin{array}{l}\text { Medication } \\
\text { Adherence }\end{array}$} & Non-adherence & Count & 34 & 35 & 69 \\
\hline & & $\begin{array}{l}\% \text { within Medication } \\
\text { Adherence }\end{array}$ & $49.3 \%$ & $50.7 \%$ & $100.0 \%$ \\
\hline & & $\%$ within DQoL & $32.1 \%$ & $42.7 \%$ & $36.7 \%$ \\
\hline & Adherence & Count & 72 & 47 & 119 \\
\hline & & $\begin{array}{l}\text { \% within Medication } \\
\text { Adherence }\end{array}$ & $60.5 \%$ & $39.5 \%$ & $100.0 \%$ \\
\hline & & $\%$ within DQoL & $67.9 \%$ & $57.3 \%$ & $63.3 \%$ \\
\hline
\end{tabular}

\section{The Relationship between Diabetes Quality of Life Domains and Medication Adherence}

The relationship between health-related quality of life and medication adherence was presented in Table 5. A significant relationship was found between the worry domain and medication adherence (Chi-Square $=10.492$, df $=1, P=0.001$ ). Meanwhile, there are no significant relationship was found between satisfaction domain (Chi-Square $=1.603, \mathrm{df}=1, P$ $=0.205$ ), impact domain (Chi-Square $=2.379, \mathrm{df}=1, P=0.123$ ) and overall health-related quality of life with medication adherence.

Table 5. Result of Chi-Square Test between Diabetes Quality of Life Domains and

\begin{tabular}{llll}
\hline Domains & Chi-Square Value & $\mathrm{df}$ & $P$-value \\
\hline Satisfaction and Medication adherence & 1.603 & 1 & 0.205 \\
Impact and Medication adherence & 2.379 & 1 & 0.123 \\
Worry and Medication adherence & 10.492 & 1 & $0.001^{* * *}$ \\
Total DQoL and Medication adherence & 2.239 & 1 & 0.135 \\
\hline
\end{tabular}

Medication Adherence

\section{Discussion}

Based on the understanding of the authors, this is one of the studies conducted in Malaysia to look on the relationship between medication adherence and health-related quality of life among T2DM patients. From this study, there is a significant relationship found between medication adherence and worry domain (Chi-Square $=0.001, \mathrm{df}=1, P=0.001$ ). There is no significant relationship was found between the satisfaction domain, impact domain and total diabetes quality of life with medication adherence among T2DM patients.

The result of the current study was supported with the findings by Shalihin, Mukhali, Zubaidi, Aris, Omar, Fauzi, \& Abdul Aziz (2019) mentioned that the number of medications intake were predicted statistically significant among old-aged diabetic patients for worry domain score in diabetes quality of life. With that, as the mean age for the current study was 64.6 years old, it may also be one of the factors that effected the domain worry to be significant with medication adherence.

Moreover, findings in the current study were in accordance with a research by Amankwah-Poku, Akpalu, Sefa-Dedeh, \& Amoah (2021) which proves that medication intake was not associated with general well-being and all the domains of quality of life because among the diabetes regimen, medication maintenance is the easiest to adhere, meanwhile other self-care routine such as diet and exercise were the most challenging regimen to be 
adhere. Furthermore, the medication intake could be a daily routine for the patient to take and therefore it has no appreciable relationship to well-being.

Lastly, past research proves that there were studies proves that the highest quality of life level in patients with diabetes mellitus was associated with better adherence treatment, meanwhile there were also few researches has not identified the association (Alfian, Sukandar, Lestari, \& Abdulah, 2016).

\section{Limitations}

The current study has its own limitations, the study was depended on the respondent's self-reported data. With that, there would be a possibility for the subject to recall bias with their answers (Alfian, Sukandar, Lestari \& Abdullah, 2016).

\section{Future Recommendations}

Firstly, other information that may influence adherence should also be assessed, such as the use of other medications, diabetes knowledge, side effect of the medication, frequency of dosage and costs of the treatment (Alfian, Sukandar, Lestari \& Abdulah, 2016). In addition, replication and adaptation of a qualitative method of this study should be conducted by taking into consideration on the previous mentioned limitations. With that, the result on the prevalence of medication adherence could be assure and generalized.

\section{Conclusion}

In conclusion, this study indicates there is a significant relationship between medication adherence and the domain worry in health-related quality of life among T2DM patients. It explained that patients with a high adherence towards their medication has a high worrying aspect in their quality of life. Moreover, these are one of the factors that can be useful to be considered in the future study. The study is also suggested to assess other variables and a qualitative study to obtain in depth understanding on T2DM patients' adherence towards their medications.

\section{Acknowledgement}

The authors acknowledged the support and guidance from the lecturers in Sultan Idris Education University (UPSI) and health care practitioners from University Malaya Medical Center (UMMC). This research was approved by the Medical Research Ethics Committee, MREC ID number: 201975-7626.

\section{Corresponding Author}

Nor Firdous Mohamed

Sultan Idris Education University, Malaysia

Email: norfirdous@fpm.upsi.edu.my

\section{Reference}

Ahmad, N. S., Ramli, A., Islahudin, F., \& Paraidathathu, T. (2013). Medication adherence in patients with type 2 diabetes mellitus treated at primary health clinics in Malaysia. Patient preference and adherence, 7, 525.

Alfian, S. D., Sukandar, H., Lestari, K., \& Abdulah, R. (2016). Medication adherence contributes to an improved quality of life in type 2 diabetes mellitus patients: A cross-sectional study. Diabetes Therapy, 7(4), 755-764. 
Aloudah, N. M., Scott, N. W., Aljadhey, H. S., Araujo-Soares, V., Alrubeaan, K. A., \& Watson, M. C. (2018). Medication adherence among patients with Type 2 diabetes: A mixed methods study. PloS one, 13(12), e0207583.

Amankwah-Poku, M., Akpalu, J., Sefa-Dedeh, A., \& Amoah, A. G. (2021). Psychosocial barriers to well-being and quality of life among type 2 diabetes patients in Ghana. Lifestyle Medicine, 2(2), e33.

Apuke, O. D. (2017). Quantitative research methods: A synopsis approach. Kuwait Chapter of Arabian Journal of Business and Management Review, 33(5471), 1-8.

Borgsteede, S. D., Westerman, M. J., Kok, I. L., Meeuse, J. C., de Vries, T. P., \& Hugtenburg, J. G. (2011). Factors related to high and low levels of drug adherence according to patients with type 2 diabetes. International journal of clinical pharmacy, 33(5), 779.

Bujang, M. A., Adnan, T. H., Hatta, M., Bariyyah, N. K., Ismail, M., \& Lim, C. J. (2018). A Revised Version of Diabetes Quality of Life Instrument Maintaining Domains for Satisfaction, Impact, and Worry. Journal of diabetes research, 2018.

Bujang, M. A., Ismail, M., Hatta, N. K. B. M., Othman, S. H., Baharum, N., \& Lazim, S. S. M. (2017). Validation of the Malay version of Diabetes Quality of Life (DQOL) questionnaire for adult population with type 2 diabetes mellitus. The Malaysian journal of medical sciences: MJMS, 24(4), 86.

Butt, M., Ali, A. M., Bakry, M. M., \& Mustafa, N. (2016). Impact of a pharmacist led diabetes mellitus intervention on $\mathrm{HbA} 1 \mathrm{c}$, medication adherence and quality of life: A randomised controlled study. Saudi Pharmaceutical Journal, 24(1), 40-48.

Chew, S., Lai, P. S. M., \& Ng, C. J. (2020). Usability and Utility of a Mobile App to Improve Medication Adherence Among Ambulatory Care Patients in Malaysia: Qualitative Study. JMIR mHealth and uHealth, 8(1), e15146.

Cho, N., Shaw, J. E., Karuranga, S., Huang, Y., da Rocha Fernandes, J. D., Ohlrogge, A. W., \& Malanda, B. (2018). IDF Diabetes Atlas: Global estimates of diabetes prevalence for 2017 and projections for 2045. Diabetes research and clinical practice, 138, 271-281.

Conn, V. S., \& Ruppar, T. M. (2017). Medication adherence outcomes of 771 intervention trials: systematic review and meta-analysis. Preventive medicine, 99, 269-276.

Cradock, K. A., ÓLaighin, G., Finucane, F. M., Gainforth, H. L., Quinlan, L. R., \& Ginis, K. A. M. (2017). Behaviour change techniques targeting both diet and physical activity in type 2 diabetes: A systematic review and meta-analysis. International Journal of Behavioral Nutrition and Physical Activity, 14(1), 18.

Demoz, G. T., Wahdey, S., Bahrey, D., Kahsay, H., Woldu, G., Niriayo, Y. L., \& Collier, A. (2020). Predictors of poor adherence to antidiabetic therapy in patients with type 2 diabetes: a cross-sectional study insight from Ethiopia. Diabetology \& Metabolic Syndrome, 12(1), 1-8.

Gillani, S. W., Ansari, I. A., Zaghloul, H. A., Sulaiman, S. A. S., Rathore, H. A., Baig, M. R., ... \& Althagfan, S. (2019). Predictors of health-related quality of life among patients with type II diabetes mellitus who are insulin users: a multidimensional model. Current Therapeutic Research, 90, 53-60.

Halali, F., Mahdavi, R., Mobasseri, M., Jafarabadi, M. A., \& Avval, S. K. (2016). Perceived barriers to recommended dietary adherence in patients with type 2 diabetes in Iran. Eating behaviors, 21, 205-210.

Hurtado, M. D., \& Vella, A. (2018). What is type 2 diabetes?. Medicine.

Iglay, K., Hannachi, H., Joseph Howie, P., Xu, J., Li, X., Engel, S. S., Moore, L. M., and Rajpathak, S. (2016) Prevalence and Co-Prevalence of Comorbidities among Patients with Type 2 
Diabetes Mellitus. Current Medical Research and Opinion, 32, 12431252.https://doi.org/10.1185/03007995.2016.1168291

Institute of Public Health. Ministry of Health Malaysia. The National Health and Morbidity Survey. (2015). Retrieved from http://iku.moh.gov.my/index.php/research-eng/list-ofresearch-eng/iku-eng/nhms-eng/nhms-2015.

Jannoo, Z., \& Khan, N. M. (2019). Medication Adherence and Diabetes Self-Care Activities among Patients with Type 2 Diabetes Mellitus. Value in health regional issues, 18, 30 35.

Khayyat, S. M., Mohamed, M. M., Khayyat, S. M. S., Alhazmi, R. S. H., Korani, M. F., Allugmani, E. B., ... \& Hadi, M. A. (2019). Association between medication adherence and quality of life of patients with diabetes and hypertension attending primary care clinics: a crosssectional survey. Quality of life research, 28(4), 1053-1061.

Khoo, E. M., Lee, W. K., Sararaks, S., Samad, A. A., Liew, S. M., Cheong, A. T., ... \& Ismail, R. (2012). Medical errors in primary care clinics-a cross sectional study. BMC family practice, 13(1), 1-6.

Malpass, A., Andrews, R., \& Turner, K. M. (2009). Patients with type 2 diabetes experiences of making multiple lifestyle changes: a qualitative study. Patient education and counseling, 74(2), 258-263.

Muhamad, N., Mutalip, M., Mustapha, N., Dali, N., Aris, T., Ismail, F., Murad, S., and Sulaiman, L. (2019). Association between Comorbidities and Selected Sociodemographic Factors with Complications of Diabetes: Results from the National Diabetic Registry Malaysia.

National Health and Morbidity Survey Malaysia. (2015). Institute of Public Health. Retrieved from

http://www.iku.gov.my/images/IKU/Document/REPORT/nhmsreport2015vol2.pdf

Presley, B., Groot, W., \& Pavlova, M. (2019). Pharmacy-led interventions to improve medication adherence among adults with diabetes: a systematic review and metaanalysis. Research in Social and Administrative Pharmacy, 15(9), 1057-1067.

Saidi, S., Sabran, N. M., Razali, R. M., Salleh, F. E. M., Soe, T., \& Jamaludin, S. (2019). Medication Adherence and Concordance among Diabetes Patient: A Mini.

Sapkota, S., Brien, J. A., Greenfield, J., \& Aslani, P. (2015). A systematic review of interventions addressing adherence to anti-diabetic medications in patients with type 2 diabetesimpact on adherence. PloS one, 10(2), e0118296.

Sefah, I. A., Okotah, A., Afriyie, D. K., \& Amponsah, S. K. (2020). Adherence to oral hypoglycemic drugs among type 2 diabetic patients in a resource-poor setting. International Journal of Applied and Basic Medical Research, 10(2), 102.

Shalihin, M. S. E. B., Mukhali, H. B. B., Zubaidi, Z. S. B. A., Aris, M. A. M., Omar, A. M., Fauzi, A. B., ... \& bin Abdul Aziz, A. A. (2019). Antidiabetic Burdens Among Geriatric Diabetic Patients And Its Association With Quality Of Life. International Journal of Allied Health Sciences, 3(3), 793-793.

Shiyanbola, O. O., Brown, C. M., \& Ward, E. C. (2018). "I did not want to take that medicine": African-Americans' reasons for diabetes medication nonadherence and perceived solutions for enhancing adherence. Patient preference and adherence, 12, 409.

Shiyanbola, O. O., Unni, E., Huang, Y. M., \& Lanier, C. (2018). Using the extended selfregulatory model to characterise diabetes medication adherence: a cross-sectional study. BMJ open, 8(11). 